Ethical approval: Chinese University of Hong Kong clinical research ethics committee.

1 Vijan S, Hayward RA. Pharmacologic lipid lowering therapy in type 2 diabetes mellitus: background paper for the American College of Physidiabetes mellitus: background pap

2 Vijan S, Hayward RA. Treatment of hypertension in type 2 diabetes mellitus: blood pressure goals, choice of agents, and setting priorities in diabetes care. Ann Intern Med 2004;138:593-602.

3 Grol R, Grimshaw J. From best evidence to best practice: effective implementation of change in patient's care. Lancet 2003;362:1225-30.

Colley C, Lucas L. Polypharmacy: the cure becomes the disease. J Gen Intern Med 1993;8:278-83.

5 Friedman R, Kazis L, Jette A, Smith M, Stollerman J, Torgerson J, et al. A telecommunications system for monitoring and counseling patients with hypertension. Impact on medication adherence and blood pressure conhypertension. Impact on medication
trol. Am J Hypertens 1996;9:285-92.

6 Robinson J, Conroy C, Wickemeyer W. A novel telephone-based system for management of secondary prevention to a low-density lipoprotein for management of secondary prevention to a low-
cholesterol $\leq 100 \mathrm{mg} / \mathrm{dl}$. Am J Cardiol 2000;85:305-8.

7 Guthrie R. The effects of postal and telephone reminders on compliance with pravastatin therapy in a national registry: results of the first myocardial infarction risk reduction program. Clin Ther 2001;23:970-80.
8 Haynes RB, McKibbon KA, Kanani R. Systematic review of randomised trials of interventions to assist patients to follow prescriptions for trials of interventions to assist $\mathrm{p}$

9 Prochaska JO, Velicer WF, Rossi JS, Goldstein MG, Marcus BH, Rakowski $\mathrm{W}$, et al. Stages of change and decisional balance for 12 problem behaviors. Health Psychol 1994;13:39-46.

10 World Health Organization. Defining adherence. In: Adherence to long-term therapies: evidence for action. Geneva: WHO, 2003:3-5. www.who.int/chronic conditions/adherencereport/en/ (last accessed 18 Jul 2006).

11 Muhlhauser I, Berger M. Patient education-evaluation of a complex intervention. Diabetologia 2002;45:1723-33.

12 Schwarzer R. Social-cognitive factors in changing health-related behaviors. Current Directions in Psychological Science 2001;10:47-51.

13 Day S, Altman D. Statistics notes: blinding in clinical trials and other studDay S, Altman D. Statistics
ies. BMJ 2000;321:504.

14 Grancelli H, Varini S, Ferrante D, Schwartzman R, Zambrano C, Soifer S, et al, for GESICA Investigators. Randomised trial of telephone intervention in chronic heart failure (DIAL): study design and preliminary observations. J Card Failure 2003;9:172-9.

(Accepted 29 June 2006)

doi $10.1136 / \mathrm{bmj} .38905 .447118 .2 \mathrm{~F}$

\title{
Underinvestigation and undertreatment of carotid disease in elderly patients with transient ischaemic attack and stroke: comparative population based study
}

Jack F Fairhead, Peter M Rothwell

\begin{abstract}
Objective To identify any underinvestigation of older patients with transient ischaemic attack (TIA) and stroke.

Design Comparative population based studies. Setting Routine clinical practice in all secondary care services in Oxfordshire and a nested population based study of incidence of transient ischaemic attack and stroke (the Oxford vascular study-OXVASC). Participants/population All patients undergoing carotid imaging for ischaemic retinal or cerebral transient ischaemic attack or stroke from 1 April 2002 to 31 March 2005 in the Oxford vascular study $(\mathrm{n}=91$ 105) and from 1 April 2002 to 31 March 2003 in routine clinical practice $(\mathrm{n}=589899)$.

Main outcome measures Age specific rates of carotid imaging, diagnosed $\geq 50 \%$ symptomatic carotid stenosis, and subsequent endarterectomy, in patients with recent transient ischaemic attack or stroke. Results Of patients with recent carotid territory transient ischaemic attack or ischaemic stroke, 575 in routine clinical practice and 402 in the Oxford vascular study had carotid imaging, with similar rates up to the age of 80 . The incidence of $\geq 50 \%$ symptomatic stenosis increased steeply with age, particularly in those aged $\geq 80$. Compared with investigations in patients in the Oxford vascular study, the rates of carotid imaging (relative rate $0.36,95 \%$ confidence interval 0.28 to $0.46, \mathrm{P}<0.0001)$, diagnosis of $\geq 50 \%$ symptomatic stenosis $(0.33,0.16$ to 0.69 , $\mathrm{P}=0.004)$, and carotid endarterectomy $(0.19,0.06$ to $0.63, \mathrm{P}=0.007)$ in this age group in routine clinical practice were all substantially lower.

Conclusions Incidence of symptomatic carotid stenosis increases steeply with age, but, despite
\end{abstract}

good evidence of major benefit from endarterectomy in elderly patients and a willingness to have surgery, there is substantial underinvestigation in routine clinical practice in patients aged $\geq 80$ with transient ischaemic attack or ischaemic stroke.

\section{Introduction}

Several audits have shown lower rates of treatment to prevent stroke in older people. ${ }^{1-4}$ Similar observations in several other specialties have led to accusations of ageism..$^{5-9}$ Lower rates of treatment in older people, however, might legitimately reflect a lack of applicable randomised evidence of effectiveness, ${ }^{10}{ }^{11}$ increased frequency of contraindications to treatment, or patients' choice. To distinguish between ageism and legitimately reduced use of stroke prevention in older people we studied rates of imaging and endarterectomy for recently symptomatic carotid stenosis. This intervention is unusual in that there is strong evidence of benefit in elderly patients, ${ }^{12}$ and good evidence that data from trials are probably generalisable to routine clinical practice. ${ }^{13}$ Nevertheless, lower rates of treatment in elderly patients could be due to a reduction in incidence of symptomatic carotid stenosis with age, contraindications to surgery, or reluctance by patients to consider surgery. To identify any evidence of inappropriate underinvestigation or undertreatment, or both, we compared age specific rates of carotid imaging, $\geq 50 \%$ symptomatic carotid stenosis, and subsequent endarterectomy in patients with recent transient ischaemic attack or stroke in a population

This article was posted on bmj.com on 18 July 2006: http://bmj.com/ cgi/doi/10.1136/bmj.38895.646898.55
Editorial by Young

Stroke Prevention Research Unit, University

Department of

Clinical Neurology,

Radcliffe Infirmary,

Oxford OX2 6HE

Jack F Fairhead

research fellow

Peter M Rothwell

professor of neurology

Correspondence to:

P M Rothwell

peter.rothwell@

clneuro.ox.ac.uk

BMJ 2006;333:525-7 
based audit of routine clinical practice in Oxfordshire with rates in a nested population based incidence study of transient ischaemic attack and stroke in which all patients were investigated as per published guidelines. ${ }^{14-16}$

\section{Methods}

Our overall study population (a one year mid-study estimate of 680 772) comprised individuals registered with the 87 primary care practices in the Oxfordshire Primary Care Trusts (routine clinical practice). Nested within this population are the participants of the Oxford vascular study (OXVASC) from nine primary care practices (three year mean 91 105). The age and sex structure and the deprivation profile of the vascular study population closely matched the remainder of the population in routine clinical practice. The methods and results of the Oxford vascular study have been published elsewhere. ${ }^{17-20}$ Case ascertainment has been shown to be extremely high for both transient ischaemic attack and stroke. ${ }^{18}{ }^{19}$ Carotid imaging was obtained in $95 \%$ of patients with transient ischaemic attack and non-disabling ischaemic stroke, and all patients were interviewed and examined so that the potential appropriateness of carotid surgery could be determined. We compared three years of ascertainment in the Oxford vascular study (1 April 2002 to 31 March 2005) with one year in routine clinical practice (1 April 2002 to 31 March 2005).

We identified all patients in routine clinical practice who had carotid imaging during the study period for a new ischaemic cerebral or retinal event by screening all NHS and private referrals for carotid ultrasonography (the main investigation for carotid disease), magnetic resonance angiography, computed tomography angiography, and conventional arterial or venous angiography in the four relevant centres in Oxfordshire and in the seven surrounding counties to ascertain cases investigated out of our primary care trust region. The detailed methods and results of this search have been reported previously. ${ }^{21} \mathrm{JFF}$ searched reports, referral letters and forms, and attendance records at each imaging centre. Out of all imaging episodes for investigation of possible transient ischaemic attack or stroke, we identified those relating to probable or definite events within the six months before the date of referral, at least one of which was consistent with carotid territory ischaemia. In all cases in which the diagnosis and indication for carotid imaging was not completely clear after assessment of the referral letters and forms, JFF summarised the hospital notes and these were then reviewed by PMR blind to population. Data on all carotid endarterectomies performed during the study period and the following year were obtained from all relevant centres in Oxfordshire by hospital diagnostic coding data and the departmental operation registers. Statistical comparisons between the two populations refer to Poisson probability.

\section{Results}

Within routine clinical practice, 875 patients were referred for carotid imaging during the year long study period, of whom 44 did not attend. Two patients had scans after two separate events, and each was included
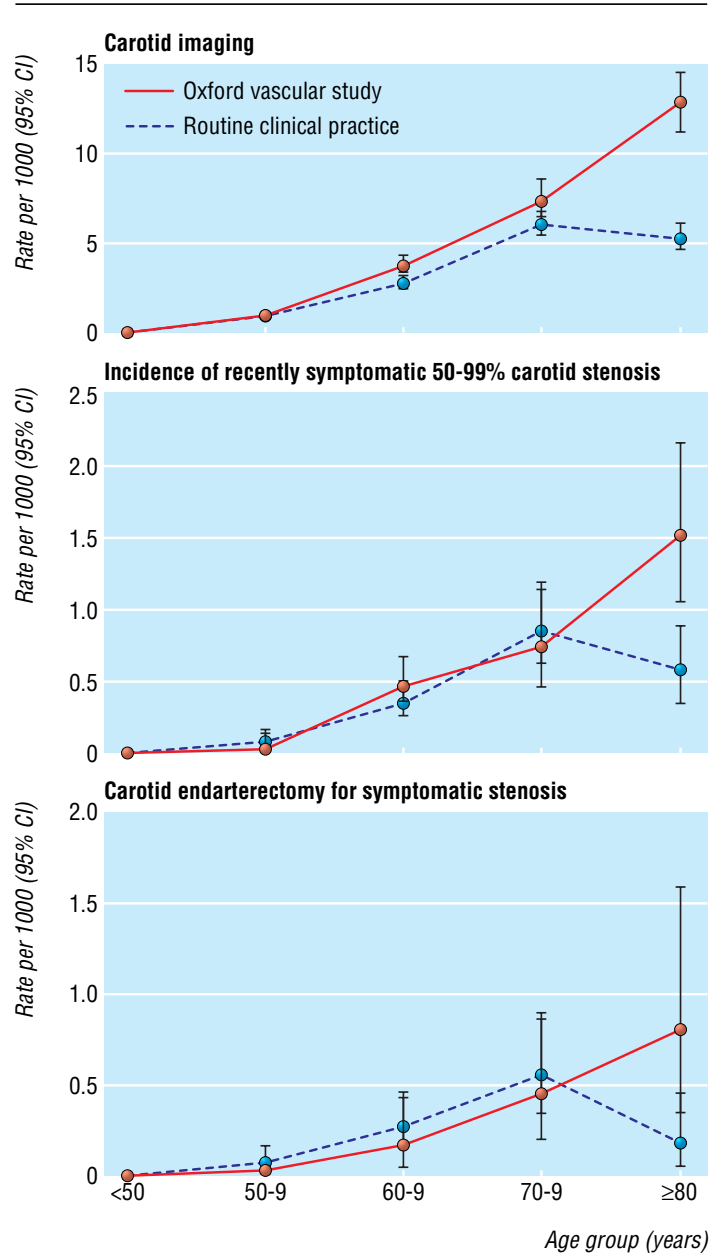

Age specific rates of carotid imaging, incidence of recently symptomatic $50-99 \%$ carotid stenosis, and carotid endarterectomy for symptomatic stenosis in the Oxford vascular study (OXVASC) and in routine clinical practice

as two patient episodes. A further 194 patients were excluded on the basis that the indication was unrelated to the investigation of a possible transient ischaemic attack or stroke, leaving 639 patients investigated. Fourteen others $(1.5 \%)$ were excluded: one Oxfordshire resident who was not registered with a primary care practice and 13 patients investigated outside Oxfordshire for whom clinical data were unavailable. Of these, $581(91 \%)$ were referred from secondary care, $19(3 \%)$ from primary care, and $38(6 \%)$ from accident and emergency departments. After further review of hospital notes, blinded to study population and results of carotid imaging, to exclude presentations that were not probable or definite carotid territory transient ischaemic attack(s) or stroke(s) within the six months before the date of referral for imaging, 575 presentations remained. These investigations identified 65 individuals with symptomatic $50-99 \%$ stenosis, of whom 42 underwent carotid endarterectomy.

We assessed completeness of ascertainment of the retrospective search strategy for carotid imaging episodes by comparison with the prospectively collected data in the first year of the Oxford vascular study (OXVASC). Only 1.3\% of patients in that study were not identified. 


\section{What is already known on this topic}

The incidence of transient ischaemic attack and stroke increases with age

Carotid imaging is an important part of the investigation of transient ischaemic attack or stroke and is recommended in all current guidelines

Elderly people benefit from carotid endarterectomy with little evidence of an increased risk of surgery

\section{What this study adds}

Transient ischaemic attack and minor stroke in elderly patients are underinvestigated, which results in undertreatment

The incidence of symptomatic carotid stenosis increases steeply in those age $\geq 80$

Within the Oxford vascular study, 472 patients were referred for carotid imaging during the three year study period. Of these, 402 were investigated for definite or probable carotid territory transient ischaemic attack or ischaemic stroke within the previous six months. This yielded 40 patients with symptomatic 50-99\% stenosis, of whom 21 had carotid endarterectomy. There was no increase in rates of carotid imaging, incidence of symptomatic 50-99\% stenosis, or carotid endarterectomy over the three years of the study.

The rates of carotid imaging increased with age in both populations (figure), but decreased at age $\geq 80$ years in routine clinical practice (relative rate $0.36,95 \%$ confidence interval 0.28 to $0.46, \mathrm{P}<0.0001)$. The incidence of diagnosed 50-99\% symptomatic carotid stenosis (figure) followed the same pattern, with a fall in routine clinical practice at age $\geq 80$ years $(0.33,0.16$ to $0.69, \mathrm{P}=0.004)$. There were no significant differences between the populations in the age specific rates of endarterectomy for recently symptomatic carotid stenosis $<80$ years (figure), but the rate in patients aged $\geq 80$ in the patients from routine clinical practice was substantially lower than that in the vascular study $(0.19$, 0.06 to $0.63, \mathrm{P}=0.007$ ). There were no operative strokes or deaths identified in either population among the 12 patients aged $\geq 80$ years who underwent endarterectomy, despite assessment by a neurologist before and 30 days after the operation in all cases.

\section{Discussion}

Rates of symptomatic carotid stenosis increase steeply with age. Patients aged $\geq 80$ with transient ischaemic attack or ischaemic stroke, however, are substantially underinvestigated in routine clinical practice. The lower rate of imaging in patients aged $\geq 80$ could be due to lower rates of referral by general practitioners to secondary care or lower rates of referral for imaging at the secondary care level (or both). We cannot differentiate between the two. The steep rise in rates of endarterectomy in patients aged $\geq 80$ in the Oxford vascular study (OXVASC), however, indicates that the fall in rates in this age group in routine clinical practice is unlikely to have been due to contraindications to treatment or to patients' choice. There was no absolute requirement that patients in the Oxford vascular study should have carotid imaging and the rate of non-attendance for imaging was, in fact, slightly higher in that study than in routine clinical practice. Moreover, the high rates of endarterectomy in patients aged $\geq 80$ in the vascular study were the result of discussions between patients and surgeons who were not involved in the study. The two populations were comparable in age, sex, and deprivation and the similar rates of investigation in those aged $<80$ suggest that disease rates were similar. We used the same methods of ascertainment of imaging data in both routine clinical practice and the vascular study and exclusion criteria were applied blinded to population source.

Contributors: JFF collected and analysed the data and wrote the paper. PMR designed the study, wrote and edited the paper, and is guarantor.

Funding: The Stroke Association and UK Medical Research Council.

Competing interests: None declared.

Ethical approval: Not required.

1 Medical Research Council Working Party. MRC trial of treatment of mild hypertension: principal results. BMJ 1985;291:97-104.

2 Rudd AG, Lowe D, Hoffman A, Irwin P, Pearson M. Secondary prevention for stroke in the United Kingdom: results from the national sentinel audit of stroke. Age Ageing 2004;33:280-6.

3 Gaw A. The care gap: underuse of statin therapy in the elderly. Int J Clin Pract 2004;58:777-85.

4 Brass LM, Krumholz HM, Scinto JM, Mathur D, Radford M. Warfarin use following ischaemic stroke among Medicare patients with atrial following ischaemic stroke among Medicil
fibrillation. Arch Int Med 1998;158:2093-100.

5 Tonks A. Medicine must change to serve an ageing society. Eradicate age Tonks A. Medicine must change to serve an ageing society. Erat
discrimination and increase resources. BMJ 1999;319:1450-1.

6 Dudley NJ, Bowling A, Bond M, McKee D, McClay Scott M, Banning A, et al. Age- and sex-related bias in the management of heart disease in a district general hospital. Age Ageing 2002;31:37-42.

7 Regueiro CR, Gill N, Hart A, Crawshaw L, Hentosz T, Shannon RP. Primary angioplasty in acute myocardial infarction: does age or race matter? J Thromb Thrombolysis 2003;15:119-23.

8 Heflin MT, Oddone EZ, Pieper CF, Burchett BM, Cohen HJ. The effect of comorbid illness on receipt of cancer screening by older people. J Am Geriatr Soc 2002:50:1651-8.

9 Dharma-Wardene MW, de Gara C, Au HJ, Hanson J, Hatcher J. Ageism in rectal carcinoma? Treatment and outcome variations. Int J Gastrointest rectal carcinoma? Trea
Cancer $2002 ; 32: 129-38$.

10 Bungeja G, Kumar A, Banerjee AK. Exclusion of elderly people from clinical research: a descriptive study of published reports. BMJ 1997;315:1059.

11 Gurwitz JH, Col NF, Avorn J. The exclusion of elderly and women from clinical trials in acute myocardial infarction. JAMA 1992;268:1417-22.

12 Rothwell PM, Eliasziw M, Gutnikov SA, Warlow CP, Barnett HJM, for the Carotid Endarterectomy Trialists Collaboration. Endarterectomy for symptomatic carotid stenosis in relation to clinical subgroups and timing of surgery. Lancet 2004;363:915-24.

13 Bond R, Rerkasem K, Cuffe R, Rothwell PM. A systematic review of the associations between age and sex and the operative risks of carotid associations between age and sex and the op
endarterectomy. Cerebrovasc Dis 2005;20:69-77.

14 Intercollegiate Stroke Working Party. National clinical guidelines for stroke. London: Royal College of Physicians, June 2004.

15 Wolf PA, Clagett GP, Easton JD, Goldstein LB, Gorelick PB, Kelly-Hayes $\mathrm{M}$, et al. Preventing ischemic stroke in patients with prior stroke and transient ischemic attack: a statement for healthcare professionals from the Stroke Council of the American Heart Association. Stroke 1999;30:1991-4.

16 Sudlow C, Lip G, Freestone B, Rothwell PM. Stroke prevention. In: Clinical Evidence. Issue 11. London: BMJ Publishing, 2004:36-9.

17 Rothwell PM, Coull AJ, Giles MF, Howard SC, Silver LE, Bull LM, et al. Change in stroke incidence, mortality, case-fatality, severity, and risk facChange in stroke incidence, mortality, case-fatality, severity, and risk fac-
tors in Oxfordshire, UK from 1981 to 2004 (Oxford vascular study). tors in Oxfordshire, UK

18 Coull AJ, Silver LE, Bull LM, Giles MF, Rothwell PM, Oxford Vascular (OXVASC) Study. Direct assessment of completeness of ascertainment in a stroke incidence study. Stroke 2004;35:2041-5.

19 Feigin V, Hoorn SV. How to study stroke incidence. Lancet 2004;363:1920.

20 Rothwell PM, Coull AJ, Silver LE, Fairhead JF. Population-based study of event rate, incidence, case fatality, and mortality for all acute vascular

21 Fairhead JF, Mehta Z, Rothwell PM. Population-based study of delays in carotid imaging and surgery and the risk of recurrent stroke. Neurology
colo lo carotid imaging
2005;65:371-5.

(Accepted 30 May 2006)

doi 10.1136/bmj.38895.646898.55 